\title{
Plasma DOPA levels and growth hormone response to levodopa in Parkinsonism
}

\author{
A. GALEA-DEbono, P. JENNER, C. D. MARSDEN, J. D. PARKES, \\ D. TARSY, AND J. WALTERS
}

From the University Department of Neurology, Institute of Psychiatry, and King's College Hospital, London

SUMMARY It has been suggested that the therapeutic response to levodopa in patients with Parkinson's disease may be related to changes in plasma growth hormone concentration. In order to examine this problem, we have determined plasma DOPA and growth hormone levels after a standard oral levodopa load in 32 patients with Parkinson's disease. Levodopa caused an increase in plasma growth hormone concentration in 30 subjects. The magnitude and timing of this growth hormone response was not related to the clinical response, the presence or absence of response swings, or the occurrence of dyskinesias. The growth hormone response to levodopa is normal in patients with Parkinson's disease and not altered by long-term levodopa treatment.

Tang and Cotzias (1976) suggested the idea that periodic growth hormone $(\mathrm{GH})$ release in response to levodopa might affect the levodopa response and account for the appearance of some varieties of 'on-off' response swings, and possibly also influence levodopa induced dyskinesias. We have studied plasma DOPA and GH levels in patients with Parkinson's disease on levodopa therapy to establish whether the levodopa-GH response is normal in Parkinsonism, and to show to what extent the antiParkinsonism response to levodopa (which is probably due to stimulation of nigrostriatal dopamine receptors) and the $\mathrm{GH}$ response (which is probably due to stimulation of hypothalamic dopamine receptors) are related.

\section{Methods}

\section{LEVODOPA-TREATED PATIENTS WITH STABLE CLINICAL RESPONSE}

Eighteen patients, 14 male and four female, aged 53-76 years (mean 65 years), with idiopathic Parkinson's disease of one to 23 years' duration (mean eight years) were investigated. All these patients had a fairly stable and sustained response to levodopa.

\section{LEVODOPA FAILURES}

Eight patients, four male and four female, aged 57-73 years (mean 63 years), with the clinical features of idiopathic Parkinson's disease of five to 15 years' duration (mean nine years) were investi-

Accepted 16 September 1976 gated. Four of these patients initially responded to levodopa, but this response was lost after one or two웅 years of treatment. The other four patients never responded to levodopa despite prolonged treatment.

LEVODOPA-TREATED PATIENTS WITH EARLY MORNING AND END-OF-DOSE AKINESIA

Six patients (A-F, see Fig. 2), five male and one female, aged 58-71 years (mean 64), with idiopathic Parkinson's disease of eight to 11 years' duration (mean nine years) were studied. These patients were much more severely disabled early in the morning than after the initial levodopa dose of each day, and all had fluctuations in response related to fluctuations in plasma DOPA levels.

\section{LEVODOPA-TREATED PATIENTS WITH 'YO-YO'} RESPONSE SWINGS

Five patients, A, B, D, E, and F, had sudden unpredictable swings in response ('yo-yo-ing', Marsden and Parkes, 1976) several times each day, not clearly related to the timing of levodopa dosage or to plasma DOPA levels.

\section{CONTROL SUBJECTS}

The GH response to levodopa was established in eight subjects, all male, aged 25-57 years (mean 34 ), including four normal healthy subjects, two with torsion dystonia and two with cervical spondylosis.

\section{MEDICATION}

Levodopa $0.25-8 \mathrm{~g}$ (18 patients) or Sinemet ( $250 \mathrm{mg}$ levodopa and $25 \mathrm{mg}$ l-alpha methyldopa hydrazine) 
three to five tablets daily (14 patients) had been given before this study for periods of 0.5 to five years. Twenty-nine of the total of 32 patients with Parkinson's disease were also taking anticholinergic drugs, and 20 were on amantadine.

\section{LEVODOPA-GH RESPONSE DETERMINATION}

Plasma GH and dopa levels were determined in 26 subjects with Parkinsonism and eight control subjects after a single dose of levodopa $1 \mathrm{~g}$ (18 subjects) or Sinemet one tablet (12 subjects). Patients A-F were given levodopa $1 \mathrm{~g}$ (one patient) or Sinemet one tablet (five patients) on four occasions at intervals of two hours.

Breakfast (carbohydrate $32 \mathrm{~g}$, fat $19 \mathrm{~g}$, and protein $17 \mathrm{~g}$ ) was given at 10.00 , and lunch $(40 \mathrm{~g}, 25 \mathrm{~g}$, and $25 \mathrm{~g}$, respectively) at 13.00 . Subjects remained fasting and recumbent for 12 hours until the initial dose of levodopa or Sinemet was given orally at 9.30 , accompanied by $500 \mathrm{ml}$ milk ( $200 \mathrm{~g}$ carbohydrate, $15 \mathrm{~g}$ fat, and $15 \mathrm{~g}$ protein).

Levodopa or Sinemet caused nausea or vomiting in one of eight control subjects, and in five of 32 patients with Parkinson's disease. Vomiting was unrelated to the magnitude or rate of increase in plasma DOPA levels, and did not appear to alter either the clinical or $\mathrm{GH}$ response.

\section{BLOOD SAMPLING}

Venous blood was taken by indwelling forearm catheter $\mathbf{3 0}$ minutes before, and at $\mathbf{3 0}$ minute intervals over a four to eight hour period after, levodopa or Sinemet was given. The concentration of levodopa and $\mathrm{GH}$ in the blood was determined by the methods of Curzon et al. (1972), and Schalch and Parker (1964) respectively.

\section{PATIENT DISABILITY}

Patient disability was assessed at $\mathbf{3 0}$ minute intervals over the trial period by the use of a score proforma (Marsden et al., 1973). The occurrence of dyskinesias was documented, and types of response swing classified according to Marsden and Parkes (1976). Clinical responses were related to plasma levels of levodopa and GH.

\section{Results}

\section{PATIENTS WITH STABLE CLINICAL RESPONSE TO LEVODOPA \\ Plasma levodopa}

Fasting plasma DOPA levels were low, less than 1.5 $\mu \mathrm{mol} / \mathrm{l}$ in all the 18 patients with a fairly stable clinical response after 0.5 to five years of levodopa treatment. The mean peak plasma DOPA concentration after levodopa $1 \mathrm{~g}$ was $5.6 \pm 1 \mu \mathrm{mol} / 1$, and after a tablet of Sinemet $4 \pm 0.5 \mu \mathrm{mol} / \mathrm{l}$. Peak plasma DOPA levels occurred earlier in patients on levodopa (range 30-90 minutes; mean 60) than on Sinemet (range 60-150 minutes; mean 103).

The peak plasma DOPA concentration after levodopa $1 \mathrm{~g}$ did not show a statistically significant correlation with age, sex, duration of Parkinsonism, period or dosage of previous levodopa treatment.

Twelve of the 18 patients with a stable clinical response to levodopa showed a slight reduction in disability score one to two hours after the oral administration of levodopa. Peak reduction in score usually, but not always, occurred at the same time as peak plasma DOPA levels. Despite the subsequent fall in plasma DOPA concentration, the clinical response remained fairly stable for four hours in most patients.

\section{Plasma growth hormone}

The fasting plasma $\mathrm{GH}$ concentration was below 2 $\mathrm{ng} / \mathrm{ml}$ in 14 of 18 patients on levodopa, and $2.1,3.5$, 7.2 , and $11.2 \mathrm{ng} / \mathrm{ml}$, respectively, in the four other patients. There was no relationship between the severity of Parkinsonism and fasting plasma GH levels. After levodopa $1 \mathrm{~g}$ or a tablet of Sinemet, there was a rise in plasma $\mathrm{GH}$ concentration greater than $5 \mathrm{ng} / \mathrm{ml}$ in 16 of 18 subjects (Fig. 1). In two subjects, there was no obvious rise in plasma $\mathrm{GH}$ levels, although peak plasma DOPA levels greater than $4 \mu \mathrm{mol} / 1$ occurred in both subjects who also showed a therapeutic response to levodopa.

The mean peak plasma $\mathrm{GH}$ concentration was $25 \pm 6.6 \mathrm{ng} / \mathrm{ml}$ in patients given levodopa, and $20 \pm 4.1$

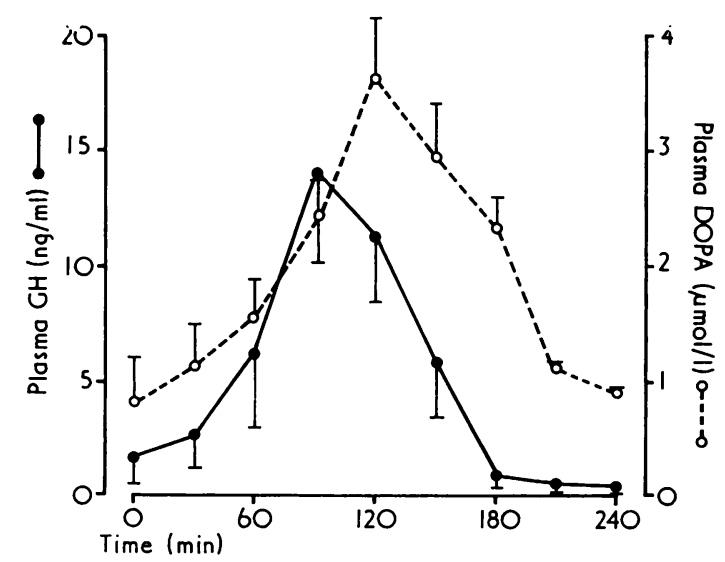

Fig. 1 Plasma DOPA ( $\mu \mathrm{mol} / \mathrm{l})$ and growth hormone $(\mathrm{GH} ; \mathrm{ng} / \mathrm{ml})$ concentration in 18 patients with Parkinson's disease with stable clinical response to levodopa, after standard oral levodopa $1 \mathrm{~g}$ load. Mean values \pm 1 SEM. 
$\mathrm{ng} / \mathrm{ml}$ in patients on Sinemet. Peak plasma GH levels occurred 30-150 minutes after levodopa or Sinemet was given.

The peak plasma GH concentration did not show a statistically significant relationship with the peak plasma DOPA concentration, reduction in disability score, age, sex, severity of Parkinsonism, duration or dosage of levodopa treatment. In most, but not all, patients peak plasma $\mathrm{GH}$ concentration occurred at the same time as peak DOPA levels, and at the same time as the greatest clinical response.

\section{LEVODOPA FAILURES}

\section{Plasma levodopa}

In these patients, peak plasma DOPA levels after a standard oral levodopa load were lower than in patients with a stable clinical response to levodopa (Table). None of these patients showed a reduction in disability score after levodopa, and none developed dyskinesias, nausea, or vomiting.

\section{Plasma growth hormone}

All eight patients who did not respond clinically to levodopa showed an increase in plasma GH concentration greater than $5 \mathrm{ng} / \mathrm{ml}$ after levodopa $1 \mathrm{~g}$ or a tablet of Sinemet. The increase in $\mathrm{GH}$ concentration was approximately as great in patients who did not respond clinically as in those who did (Table).

\section{LEVODOPA REVERSAL OF EARLY MORNING AKINESIA Plasma levodopa}

Mean peak plasma DOPA levels after levodopa $1 \mathrm{~g}$ or Sinemet one tablet were similar in patients A-F, and in the 18 patients with a much more stable clinical response. Plasma DOPA and GH levels in patients $\mathrm{A}-\mathrm{F}$ are shown in Fig. 2. The mean peak plasma DOPA concentration was $6.6 \pm 0.3 \mu \mathrm{mol} / 1$ after the initial levodopa or Sinemet dosage; $6.1 \pm 0.7 \mu \mathrm{mol} / 1$ after the second; and $4.6 \pm 0.2 \mu \mathrm{mol} / 1$ after the third. In patients $A, C, D$, and $E$, plasma DOPA levels fluctuated after separate Sinemet dosages.

Reversal of early morning akinesia in patients
A-F occurred at the same time as the initial increase in plasma DOPA concentration. On the day of test, there was little change in total disability score over the eight hours test period in patient $C$. In the other patients, total disability scores varied considerably over the test period. With the two hourly oral levodopa or Sinemet dosage schedule followed, clearly defined end-of-dose akinesia did not occur or could not be distinguished from 'yo-yo' episodes. Overall, disability was least when the plasma DOPA concentration was high, and greatest when it was low. At the time of greatest clinical response, the mean plasma DOPA concentration was $3.6 \pm 1$ $\mu \mathrm{mol} / \mathrm{l}$, and at the time of least therapeutic response, after the initial morning improvement, but excluding 'off' periods during 'yo-yo' episodes, it was $2.5 \pm 0.5$ $\mu \mathrm{mol} / \mathrm{l}$. However, in patients $\mathrm{A}-\mathrm{F}$, clinical improvement (reduction in total disability score compared with morning pre-treatment values) was not directly related at any one time to the plasma DOPA concentration at the same time, or that occurring 30 minutes previously $(r=0.18$ and 0.14 respectively, in both cases $\mathrm{P}>0.1, \mathrm{NS}$ ).

\section{Plasma growth hormone}

The fasting plasma GH levels were low $(0.5-5 \mathrm{ng} / \mathrm{ml})$ in patients $A-E$, and high $(12 \mathrm{ng} / \mathrm{ml})$ in patient $F$ (Fig. 1). After Sinemet, the mean peak plasma GH concentration was $18 \pm 5 \mathrm{ng} / \mathrm{ml}$ after the first dosage $5 \pm 1 \mathrm{ng} / \mathrm{ml}$ after the second; and $4 \pm 1 \mathrm{ng} / \mathrm{ml}$ after the third.

After levodopa or Sinemet, the peak plasma $\mathrm{GH}$ concentration occurred within 30 minutes of the time of peak plasma DOPA concentration on most, but not all occasions. As in patients with a stable clinical response, there was no statistically significant relationship between the peak plasma DOPA and GH concentration in patients with a fluctuating response $(r=0.19, \mathrm{P}>0.1$, NS).

Fluctuations of clinical response were sometimes, but not always, accompanied by fluctuations in plasma GH levels and did not always occur at the

Table Mean age, peak plasma DOPA and GH concentrations after levodopa $1 \mathrm{~g}$ or Sinemet one tablet (25 mg l-alpha methyl dopa hydrazine and $250 \mathrm{mg}$ levodopa) in different patient groups

\begin{tabular}{|c|c|c|c|c|c|c|}
\hline & \multirow{2}{*}{$\begin{array}{l}\text { No. of } \\
\text { patients }\end{array}$} & \multicolumn{3}{|c|}{ Mean age } & \multicolumn{2}{|c|}{ Mean peak plasma } \\
\hline & & Male & Female & $(y r)$ & 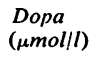 & $\begin{array}{l}\text { Plasma } G H \\
(n g / m l)\end{array}$ \\
\hline $\begin{array}{l}\text { Subjects without Parkinsonism } \\
\text { Parkinson's disease: stable levodopa response } \\
\text { First year of levodopa treatment } \\
\text { Second-fifth year of levodopa treatment } \\
\text { DOPA swingers } \\
\text { DOPA failures }\end{array}$ & $\begin{array}{r}8 \\
18 \\
6 \\
12 \\
6 \\
8\end{array}$ & $\begin{array}{r}8 \\
14 \\
5 \\
9 \\
5 \\
4\end{array}$ & $\begin{array}{l}-4 \\
1 \\
3 \\
1 \\
4\end{array}$ & $\begin{array}{l}34 \\
65 \\
63 \\
66 \\
64 \\
63\end{array}$ & $\begin{array}{l}6.6 \pm 0.5 \\
4.6 \pm 0.5 \\
4.7 \pm 1.1 \\
4.6 \pm 0.5 \\
6.6 \pm 0.5 \\
2.5 \pm 0.5\end{array}$ & $\begin{array}{l}32 \pm 4^{*} \\
22 \pm 3.3 \\
24 \pm 6.9 \\
21 \pm 3.7 \\
18 \pm 5.2 \\
19 \pm 2.7\end{array}$ \\
\hline
\end{tabular}

*Difference peak plasma GH, non-Parkinsonism: Parkinsonism subjects, P $<0.01$, Student's $t$ test.

$\dagger$ Difference peak plasma DOPA, DOPA failures: DOPA responders, $\mathrm{P}<0.01$, Student's $t$ test. 


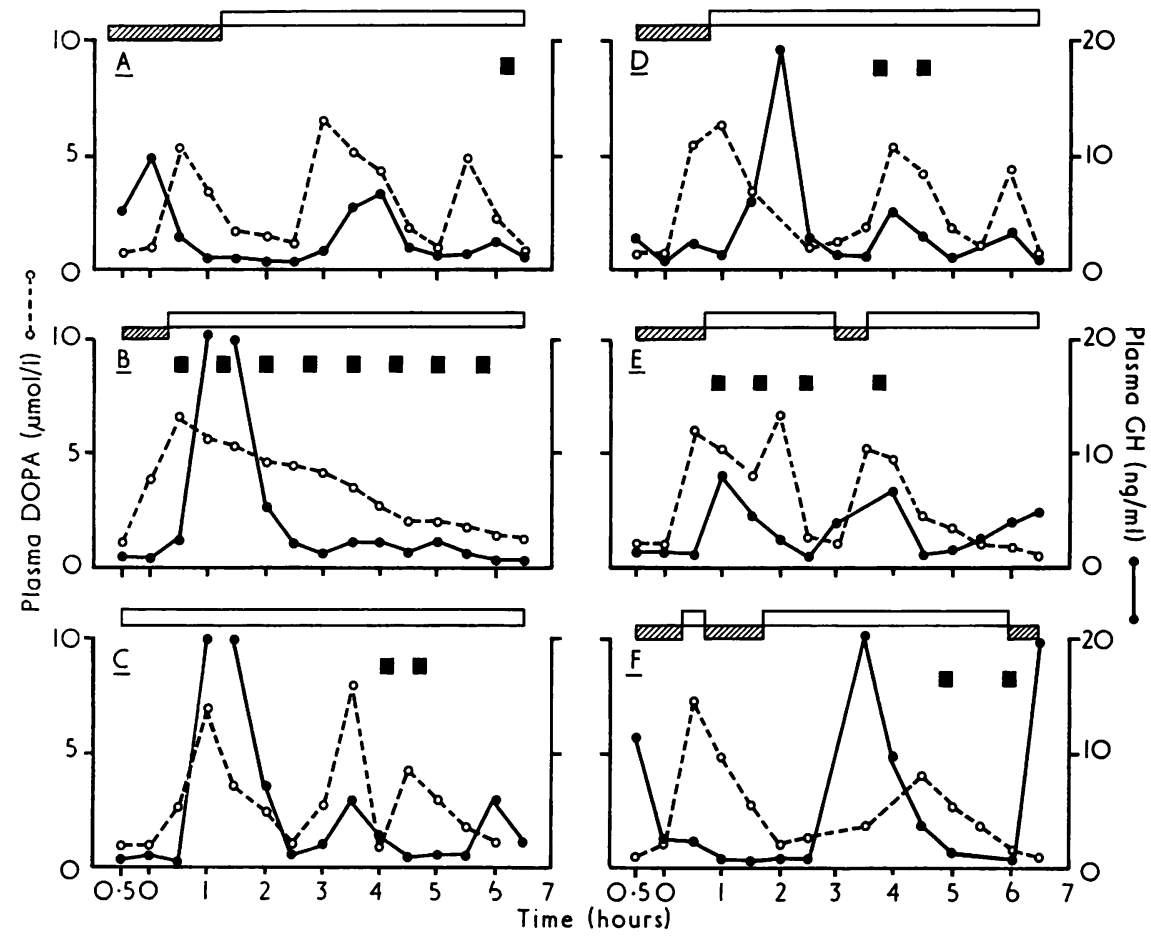

Fig. 2 Individual plasma DOPA $(\mu \mathrm{mol} / \mathrm{l})$ and growth hormone ( $\mathrm{GH}$; $n g / m l)$ concentration in six patients $(A-F)$ with Parkinson's disease who had developed severe response swings during levodopa therapy. All patients were given four separate oral dosages of Sinemet one tablet $(A-E)$ or levodopa $1 \mathrm{~g}(F)$ at two hour intervals during an eight hour test period. The time of occurrence of severe levodopa dyskinesias and marked response swings is indicated. a levodopa dyskinesias. $\square$ : on. V: off.

same time as gross changes in plasma GH concentration.

\section{'YO-YO' RESPONSE SWINGS \\ Plasma levodopa}

Two patients, E and F, had definite 'yo-yo' episodes during the trial period. These response swings occurred 30-120 minutes after initial or subsequent levodopa dosages, and lasted for 10-30 minutes. In patient $F$, there was a fall in plasma DOPA concentration before two swings from mobility to akinesia, which occurred 45 minutes and 120 minutes after separate doses of levodopa. In patient E, 'yo-yo' response swings occurred 60 minutes after oral Sinemet dosage, accompanying fluctuation in plasma DOPA concentration from 6.1 to $1.6 \mu \mathrm{mol} / 1$. Similar fluctuations in plasma DOPA concentration occurred in patients $A, C$, and $D$, but 'yo-yo' response swings did not occur.

\section{Plasma growth hormone}

In patient $\mathrm{F}$, a 'yo-yo' response swing occurred when the plasma GH concentration was low, while on two other occasions (patients E and F) a 'yo-yo' response occurred simultaneously with a rise in plasma $\mathbf{G H}$ concentration.
LEVODOPA DYSKINESIAS

\section{Plasma levodopa}

Plasma DOPA and GH concentrations were determined in patients A-F during levodopa dyskinesias. The timing and occurrence of dyskinesias are shown in Fig. 2. In most patients, dyskinesias were of greatest severity when the plasma DOPA concentration was high, but in one patient dyskinesias were equally severe when the plasma DOPA concentration was low $(1.3 \mu \mathrm{mol} / \mathrm{l})$, and high $(6.1 \mu \mathrm{mol} / \mathrm{l})$.

\section{Plasmagrowth hormone}

In patients $\mathrm{A}-\mathrm{F}$, levodopa induced dyskinesias mainly occurred when the plasma GH concentration was high, although in patient $\mathrm{B}$, dyskinesias were also present when the plasma GH concentration was low (4 $\mathrm{ng} / \mathrm{ml})$.

\section{SUBJECTS WITHOUT PARKINSONISM \\ Plasma levodopa}

The mean peak plasma DOPA concentration after levodopa $1 \mathrm{~g}$ was higher in eight subjects who did not have Parkinson's disease than in 24 subjects with Parkinson's disease who responded to levodopa treatment (Table) There was a considerable variation 
in peak plasma DOPA concentration in individual controls and subjects with Parkinsonism.

\section{Plasmagrowth hormone}

All normal subjects had an increase in plasma GH concentration after levodopa $1 \mathrm{~g}$. The increase in mean peak plasma $\mathrm{GH}$ concentration after levodopa was significantly greater in eight control subjects than in 24 patients with Parkinsonism. However, mean peak plasma DOPA levels were higher in control than in Parkinsonism subjects, individual patients with Parkinson's disease had as great a rise in plasma GH concentration after levodopa as did control subjects, and the mean age of control subjects was lower than that of patients with Parkinson's disease.

\section{Discussion}

In normal subjects, exercise increases production of growth hormone (GH), and in Parkinsonism, akinesia may be associated with reduced resting plasma GH levels. Mena et al. (1973) reported that basal plasma GH levels were low in untreated patients. The stress of vomiting caused by levodopa may influence $\mathrm{GH}$ responses in normal and Parkinsonism subjects, and Malarkey et al. (1974) found that the expected GH response to levodopa was lost after chronic treatment. However, most of the patients we studied had a rise in plasma GH concentration after levodopa, despite several years of treatment, as was found also by Lebovitz et al. (1974). The GH response to insulin hypoglycaemia is possibly reduced in Parkinsonism (Lebovitz et al., 1974), although this is not always so (Werder et al., 1970). Minor differences in GH response to catecholamines and other stimuli in Parkinsonism and normal subjects are likely to result from differences in age, or akinesia. The rise in plasma GH concentration after levodopa or the dopamine agonist apomorphine is lower in old than young people (Sachar et al., 1972; Maany et al., 1975), and the difference in peak plasma GH concentration after levodopa that we observed in Parkinsonism and normal subjects, may have been due largely if not entirely to difference in age.

There does not seem to be any practical consequence of the periodic hormonal changes caused by levodopa in Parkinsonism. In levodopa-treated patients, a number of possible hormonal effects have, however, been recorded, including a high incidence of goitre (Eddy et al., 1971), post-menopausal bleeding (Kruse-Larsen and Garde, 1971), and hypersexuality in the male (Barbeau, 1969).

The different kinds of response variation that occur in levodopa-treated patients with Parkinsonism have different causes (Barbeau, 1972; Marsden and
Parkes, 1976). However, as judged by the GH data, none of the response swings that we have investigated appears to result from either an increased or a decreased receptor sensitivity to dopamine. The therapeutic effect of a single oral dose of levodopa lasts two to four hours (Muenter and Tyce, 1971). Periods of relative akinesia are most commonly associated with low DOPA levels, and mobility with high levels (Sweet and McDowell, 1972; Fahn, 1974; Tolosa et al., 1975). Intravenous levodopa and the maintenance of steady plasma DOPA levels will avoid this type of fluctuation (Shoulson et al., 1975). In contrast to early morning and end-of-dose akinesia, 'yo-yo' response swings are unpredictable in time and not clearly related to the plasma DOPA concentration. Changes in plasma GH concentration had little definite relationship with variations in clinical response of this type.

It is improbable that the increase in plasma $\mathrm{GH}$ concentration caused by levodopa is important in the anti-Parkinsonism effect of this drug, since patients who did not have an increase, did make a therapeutic response. However, Cotzias et al. (1976) suggested that metabolic changes as a result of GH release might modify the effects of anti-Parkinsonisn drugs. The antagonist of $\mathrm{GH}$, somatostatin, antage onises the effects of $\mathrm{GH}$ on apomorphine ane levodopa in animals.

The causes of failure to respond to levodopa if Parkinsonism are complex. The diagnosis of idio pathic Parkinson's disease is sometimes difficult, an other conditions with similar clinical features, such a striatonigral degeneration may be present, in which the response to levodopa is limited. Extreme depletion of striatal decarboxylase may theoretically occur, and striatal formation of dopamine may be impossible despite large doses of levodopa (Calne et al., 1974). Competition between levodopa and other dietary amino acids may prevent adequate quantities of levodopa penetrating the brain, and so be responsible for response fluctuations or failure (Mena and Cotzias, 1975). In other patients, and possibly those we studied who did not respond to levodopa, absorption of levodopa from the gastrointestinal tract may be erratic or delayed. However, in these patients who did not have, or who had lost, all clinical response to levodopa, the levodopa-GH response was normal, indicating that dopamine-stimulation of $\mathrm{GH}$ systems had occurred.

We gratefully acknowledge the support of the Parkinson's Disease Society of the UK. A.G.D. was supported by a grant from the Joint Research Committee of King's College Hospital and Medical School, and the Institute of Psychiatry. 


\section{References}

Barbeau, A. (1969). L-dopa therapy in Parkinson's disease: a critical review of nine years' experience. Canadian Medical Journal, 101, 59-68.

Barbeau, A. (1972). Long term appraisal of levodopa therapy. Neurology (Minneap.), 22, 22-24.

Calne, D. B., Teychenne, P. F., Claveria, L. E., Eastman, R., Greenacre, J. K., and Petrie, A. (1974). Bromocriptine in parkinsonism. British Medical Journal, 4, 442-444.

Cotzias, G. C., Papavasiliou, P. S., Tolosa, E. S., Mendez, J. S., and Bell-Midura, M. (1976). Treatment of parkinsonism with aporphines; a possible role of growth hormone. New England Journal of Medicine, 294, 567-572.

Curzon, G., Kantamaneni, B. D., and Trigwell, J. (1972). A method for the determination of dopa and 3-Omethyldopa in the plasma of parkinsonian patients. Clinica Chimica Acta, 37, 335-341.

Eddy, R. L., Jones, A. L., Chakmakjian, Z. H. and Silverthorne, M. C. (1971). Effect of levodopa (L-Dopa) on human hypophyseal trophic hormone release. Journal of Clinical Endocrinology and Metabolism, 33, 709-712.

Fahn, S. (1974). On-off phenomenon with levodopa therapy in parkinsonism. Neurology (Minneap.), 24, 431-434.

Kruse-Larsen, C., and Garde, K. (1971). Post menopausal vaginal bleeding on dopa. Lancet, 1, 707-708.

Lebovitz, H. E., Skyler, J. S., and Boyd, A. F. (1974). L-dopa and growth hormone secretion in man. In Advances in Neurology, vol. 5, pp. 461-469. Edited by F. McDowell and A. Barbeau. Raven Press: New York.

Maany, A., Frazier, A., and Mendels, J. (1975). Apomorphine-effect on growth hormone. Journal of Clinical Endocrinology and Metabolism, 40, 162-163.

Malarkey, W. B., Cyrus, J., and Paulson, G. W. (1974). Dissociation of growth hormone and prolactin secretion in Parkinson's disease following chronic 1-dopa therapy. Journal of Clinical Endocrinology and Metabolism, 39, 229-235.

Marsden, C. D., Barry, P. E., Parkes, J. D., and Zilkha, K. J. (1973). Treatment of Parkinson's disease with levo- dopa combined with l-alpha-methyldopa hydrazine, an inhibitor of extracerebral DOPA decarboxylase. Journal of Neurology, Neurosurgery and Psychiatry, 36, 10-14.

Marsden, C. D., and Parkes, J. D. (1976). 'On-off' effects in patients with Parkinson's disease on chronic levodopa therapy. Lancet, 1, 292-296.

Mena, I., and Cotzias, G. C. (1975). Protein intake and treatment of Parkinson's disease with levodopa. New England Journal of Medicine, 292, 181-184.

Mena, I., Cotzias, G. C., Brown, F. C., Papavasiliou, P. S., and Miller, S. T. (1973). Defective release of growth hormone in parkinsonism improved by levodopa. New England Journal of Medicine, 288, 320-321.

Muenter, M. D., and Tyce, G. M. (1971). L-dopa therapy of Parkinson's disease: plasma l-dopa concentration, therapeutic response and side effects. Mayo Clinic Proceedings, 46, 231-239.

Sachar, E. J., Mushrush, G., Perlow, M., Weitzman, E. D., and Sassin, J. (1972). Growth hormone responses to l-dopa in depressed patients. Science, 178, 1304-1305.

Schalch, D. S., and Parker, M. L. (1964). A sensitive double antibody immunoassay for human growth hormone in plasma. Nature, 203, 1141-1142.

Shoulson, I., Glaubiger, G. A., and Chase, T. N. (1975). On-off response. Clinical and biochemical correlations during oral and intravenous levodopa administration in parkinsonian patients. Neurology (Minneap.), 25, 1144-1148.

Sweet, R. D., and McDowell, F. H. (1972). Plasma dopa concentration and the 'on-off' effect after chronic treatment of Parkinson's disease. Neurology (Minneap.), 24, 953-956.

Tang, L. C., and Cotzias, G. C. (1976). Modification of the actions of some neuroactive drugs by growth hormone. Archives of Neurology (Chic.), 33, 131-134.

Tolosa, E. S., Martin, W. E., Cohen, H. P., and Jacobson, R. L. (1975). Patterns of clinical response and plasma dopa levels in Parkinson's disease. Neurology (Minneap.), 25, 177-183.

Werder, K. V., Van Loon, G. R., Yatsu, F., and Forsham, P. H. (1970). Corticosteroid and growth hormone secretion in patients treated with l-dopa. Klinische Wochenschrift, 48, 1454-1456. 